\title{
Prevalence of Night Blindness among Children in Elhag Yousif Area, Khartoum, Sudan
}

\author{
Mohammed. A. Elzain1, Mohammed. A. Elawad2, Tawfig. M. Ali3 \\ 1 Ministry of Health, Sudan \\ 2Department of Epidemiology, Faculty of Public and Environmental Health University of Khartoum, Sudan, \\ 3 Department of Public Health, College of Health Sciences at Alith, Umm Al-Qura University, Saudi Arabia
}

\begin{abstract}
A cross-sectional community-based study was conducted in El-Hag Yousif area, Khartoum, Sudan to measure the prevalence of night blindness in children. A total of 272 children were selected from four clusters in the study area using simple random sample technique. The diagnosis of night blindness was based on World Health Organization criterion which is identifying the blind children by lack of vision or inability to see well at night or in dim light. The prevalence of night blindness among children was $2.6 \%$. The prevalence in females was $1.5 \%$, males $1.1 \%$, and in children less than 4 years was $4.2 \%$. No statistical association found between night blindness and child sex and age. There was statistical significance of lack of vitamin A supplementation on prevalence of night blindness (Relative Risk $=4.732,95 \%$ Confidence Interval from 1.337 to 16.749). The study concluded that the prevalence of night blindness was high and application of vitamin A supplementary was rapidly needed to prevent increasing of the problem.
\end{abstract}

Key Words: prevalence, night, blindness, vitamin A, children, Sudan.

\section{Introduction}

Night blindness is one of the earliest signs of vitamin A deficiency [1]. The physical symptoms of night blindness are xerophthalmia, Pinot spots, karatomalacia and Cornea ulceration [2]. Vitamin A is an essential nutrient needed in small amounts for the normal functioning of the visual system [3]. Childhood blindness in developing countries is a result of many factors such as measles; one of these factors is vitamin A deficiency [4]. Approximately 250,000-500,000 children in the developing countries become blind each year due to vitamin A deficiency, with highest prevalence in Africa and South East Asia [1]. In areas where VAD is common there is usually one or more phrase in the local language for the inability to see well at night [5].

Health consequences of vitamin A deficiency include mild to severe systemic effects on innate and acquired mechanisms of host resistance to infection and growth, increased burden of infectious morbidity, mild to severe (blinding) stages of xerophthalmia, and increased risk of mortality [6]. Prevalence of vitamin A deficiency was found to be $8.3 \%$ as indicated by conjunctival and corneal xerosis, while $0.9 \%$ had night blindness [7]. The incidence of night blindness was to be $0.9 \%$ in a study conducted among khalwa students which is a non-governmental boarding school specialized in teaching Quran to Sudanese children [1].

\subsection{Study Area}

\section{Materials And Methods}

El-Hag Yousif area is located in Sharg Al-Nil locality, Khartoum capital of the Sudan. It is populated by 542289 persons. The number of children in the area is 125257 . It is divided into 12 clusters. The socioeconomic status of population in the area is poor compared to other areas in Khartoum. It lacks necessary health services such sufficient safe water, sanitary disposal of sewage, equipped hospitals and others.

\subsection{Study Population and Sampling}

The study population was children up to 15 years in the area. About 272 of them were determined as a sample size according to statistical equation. Four clusters out of the twelfth clusters were selected randomly to be included in the study. The study group was selected from studied clusters equally. Inside cluster, simple random sample technique was used.

\subsection{Ethical Clearance}

Ethical clearance was obtained from Khartoum State Ministry of Health. Informed consents were given by families of studied children.

\subsection{Data Collection and Analysis}

A questionnaire was used to collect data from study group. Most of children mothers have participated in answering the questions. The diagnosis of night blindness based on World Health Organization diagnostic 
criterion which is lack of vision or inability to see well at night or in dim light. Statistical tests i.e. odds ratio, $p$ value and relative risk were used to measure the association between different variables.

\section{Results}

The prevalence of night blindness among children in Elhag Yousif Area, Khartoum, Sudan was 26\% (table 1). The prevalence among females was $1.5 \%$ while in males was $1.1 \%$ (table 2). In table 3 , prevalence of night blindness in children less than 4 years was $4.2 \%$, in age group $4-7$ was $2.3 \%$, in age group $8-11$ was $1.3 \%$ and in age group $12-15$ was $2.8 \%$. The prevalence of night blindness in children who were not receiving vitamin A dose was $11.1 \%$ while among those receiving vitamin A supplementary the prevalence was $0.8 \%$ (Relative Risk $=4.732,95 \%$ Confidence Interval from 1.337 to 16.749 ) as shown in table 4 .

Table (1) Prevalence of night blindness among children in Elhag Yousif Area, Khartoum, Sudan $(\mathbf{n}=272)$

\begin{tabular}{|l|c|c|}
\hline Night blindness & No & $\%$ \\
\hline Blind & 7 & $2.6 \%$ \\
\hline Not blind & 265 & $97.4 \%$ \\
\hline Total & 272 & $100 \%$ \\
\hline
\end{tabular}

Table (2) Sex distribution of night blindness among children in Elhag Yousif Area, Khartoum, Sudan

\begin{tabular}{|l|c|c|c|c|c|c|c|c|}
\hline \multirow{2}{*}{ Sex } & \multicolumn{2}{|c|}{ Blind } & \multicolumn{2}{c|}{ Not blind } & \multicolumn{2}{c|}{ Total } & \multirow{2}{*}{ OR } & \multirow{2}{*}{$95 \%$ CI } \\
\cline { 2 - 8 } & No & $\%$ & No & $\%$ & No & $\%$ & & \multirow{2}{*}{$0.171-3.5476$} \\
\hline Male & 3 & $1.1 \%$ & 130 & $47.9 \%$ & 133 & $48.9 \%$ & \\
\hline Female & 4 & $1.5 \%$ & 135 & $49.5 \%$ & 139 & $51.1 \%$ & 0.7788 & $0.17 \%$ \\
\hline Total & 7 & $2.6 \%$ & 265 & $97.4 \%$ & 272 & $100 \%$ & & \\
\hline
\end{tabular}

$\mathrm{OR}=$ Odds Ratio, $\mathrm{CI}=$ Confidence Interval

Table (3) Age distribution of night blindness among children in Elhag Yousif Area, Khartoum, Sudan $(\mathbf{n}=272)$

\begin{tabular}{|c|c|c|c|c|c|c|c|c|}
\hline \multirow{3}{*}{ Age ( years) } & \multirow{2}{*}{\multicolumn{2}{|c|}{ Blind }} & \multirow{2}{*}{\multicolumn{2}{|c|}{ Not blind }} & \multirow{2}{*}{\multicolumn{2}{|c|}{ Total }} & \multirow[b]{3}{*}{ Chi square } & \multirow[b]{3}{*}{$\mathrm{P}$ value } \\
\hline & & & & & & & & \\
\hline & No & $\%$ & No & $\%$ & No & $\%$ & & \\
\hline$>4$ & 3 & $4.2 \%$ & 69 & $95.8 \%$ & 72 & $26.5 \%$ & \multirow{5}{*}{1.26} & \multirow{5}{*}{0.74} \\
\hline $4-7$ & 2 & $2.3 \%$ & 85 & $97.7 \%$ & 87 & $32 \%$ & & \\
\hline $8-11$ & 1 & $1.3 \%$ & 76 & $98.7 \%$ & 77 & $28.3 \%$ & & \\
\hline $12-15$ & 1 & $2.8 \%$ & 35 & $97.2 \%$ & 36 & $13.2 \%$ & & \\
\hline Total & 7 & $2.6 \%$ & 265 & $97.4 \%$ & 272 & $100 \%$ & & \\
\hline
\end{tabular}

Table (4) Relationship between Vitamin A supplementary and night blindness among children in Elhag Yousif Area, Khartoum, Sudan $(n=272)$

\begin{tabular}{|c|c|c|c|c|c|c|c|c|}
\hline \multirow[b]{2}{*}{ Vitamin A dose } & \multicolumn{2}{|c|}{ Blind } & \multicolumn{2}{|c|}{ Not blind } & \multicolumn{2}{|c|}{ Total } & \multirow[b]{2}{*}{$\mathrm{RR}$} & \multirow[b]{2}{*}{$95 \% \mathrm{CI}$} \\
\hline & No & $\%$ & No & $\%$ & No & $\%$ & & \\
\hline Not received & 2 & $11.1 \%$ & 16 & $88.9 \%$ & 18 & $6.6 \%$ & \multirow{3}{*}{4.732} & \multirow{3}{*}{$1.337-16.749$} \\
\hline Received & 5 & $0.8 \%$ & 249 & $99.2 \%$ & 254 & $93.4 \%$ & & \\
\hline Total & 7 & $2.6 \%$ & 265 & $97.4 \%$ & 272 & $100 \%$ & & \\
\hline
\end{tabular}

$\mathrm{RR}=$ Relative Risk, CI = Confidence Interval

\section{Discussion}

Night blindness among children is a serious public health problem due to its effect on their health and daily activities. The problem is due to several factors, however the main reasons is vitamin A deficiency (VAD). The present study measured the prevalence of night blindness in children as a community-based study, and it was found to be $2.6 \%$. Although, it is high prevalence compared with other regions, Abdelmoneim et al (2012) in a survey conducted in Sudan at Umm-dawanban Maseed, a traditional boarding school, where the Quran is taught, found that the prevalence of night blindness was 23.6\%. Also Mohammed et al (2014) reported that the incidence of night blindness was to be $0.9 \%$ In a study conducted among khalwa students which is a nongovernmental boarding school specialized in teaching Quran to Sudanese children [1].

In the present study it has been observed that night blindness has no association neither with child sex (odds ratio $=0.7788,95 \%$ confidence interval $=0.171-3.5476)$ nor with child age $\left(x^{2}=1.26, p\right.$ value $\left.=0.74\right)$ in developing night blindness. Also it was found that no significant association was observed between the differences in mean age and development of night blindness $(\mathrm{P}=0.657)$ [8]. 
Vitamin A was associated with night blindness; the prevalence of night blindness was low in children who received doses of vitamin A supplementation (Relative Risk $=4.732,95 \%$ Confidence Interval from 1.337 to 16.749). Despite the small amount of vitamin A that the human body needs and the availability of the vitamin in different types of cheap vegetables, many children suffering vitamin A deficiency. It might be attributed to metabolic disturbance or loss of the vitamin in diarrhea. Vitamin A supplementation is required to improve the vitamin status. Periodic delivery of highpotency supplements of vitamin A to children is one of night blindness control [3].

\section{Conclusion}

The study concluded that the prevalence of night blindness was high and application of vitamin A supplementary was rapidly needed to prevent increasing of the problem.

\section{Acknowledgement}

We would like to thank Administration of El-Hag Yousif locality and opinion leaders in the study area for their permission to carry out the survey. Also thanks go to children and their parents for their collaboration and participation willingly in the study.

\section{References}

[1] M. O. Swar, I. Alhaj, A. M. Osman, (2014), Vitamin A-rich porridge for Boarding Khalwa students with night blindness, Sudanese Journal of Paediatrics; 14(1), 2014, $45-50$.

[2] S. M. Ali, H. O. El Hag, Factors Influencing Anemia and Night Blindness among Children Less than Five Years Old (0 - 4.11 Years) in Khartoum State, Suda, International Journal of Scientific Research in Knowledge, 1(7), 2013, $189-201$.

[3] WHO. Global prevalence of vitamin A deficiency in populations at risk 1995-2005. WHO Global Database on Vitamin A Deficiency (Geneva, World Health Organization, 2009).

[4] A. Tagelsir, A. E. Khogli, N. M. Nurelhuda, Oral health of visually impaired schoolchildren in hartoum State, Sudan, BMC Oral Health, 2013, 13:33

[5] D. S. Mclaren, M. Frigg, Sight and Life Guidebook on Vitamin A in Health and Disease, 2nd ed. Switzerland ,Task Force, 2001)

[6] W. Keith, Vitamin A deficiency disorders in children and women, Food \& Nutrition Bulletin, 24(2), 2003, 78-90(13)

[7] N. Mamoun, S. Homedia, M. Mabyou, H. M. Ahmed, M. T. Salah, I. Adam, Prevalence, Types and Risk Factors for Malnutrition in Displaced Sudanese Children, American Journal of Infectious Diseases, 1 (2), 2005, 84-86.

[8] A. E. Kheir, T. O. Dirar1, H. O. Elhassan1, M. A. Elshikh1, M. B. Ahmed, M. A. Abbass, S. S. Idris, Xerophthalmia in a Traditional Quran Boarding School in Sudan, Middle East African Journal of Ophthalmology, 19( 2), 2012,190 - 193. 